\title{
Outcome of univentricular repair in patients with Down syndrome
}

\author{
Takeshi Furukawa, MD, ${ }^{\mathrm{a}, \mathrm{b}}$ In-Sam Park, MD, ${ }^{\mathrm{b}}$ Tadahiro Yoshikawa, MD, ${ }^{\mathrm{b}}$ Tomomi Nishimura, MD, \\ Yukihiro Takahashic, $\mathrm{MD},{ }^{\mathrm{c}}$ Makoto Ando, $\mathrm{MD},{ }^{\mathrm{c}}$ and Naoki Wada, $\mathrm{MD}^{\mathrm{c}}$
}

\begin{abstract}
Objective: Total cavopulmonary connection (TCPC) is rarely performed for a functional single ventricle in children with Down syndrome; therefore, the postsurgical outcomes are not well known. We evaluated mortality and related factors after TCPC in children with Down syndrome.
\end{abstract}

\begin{abstract}
Methods: Between January 2004 and March 2010 we identified 8 patients with Down syndrome among 235 patients who had undergone TCPC. The preoperative clinical course, preoperative data, and postoperative clinical course were evaluated. In addition, clinical parameters and postoperative clinical course were compared between children with Down syndrome $(n=8)$ and a non-Down syndrome group $(n=227)$.

Results: The median age at the time of TCPC was 4.1 years (range, 3.4-5.5 years), and the preoperative mean pulmonary artery pressure was $13.9 \pm 1.81 \mathrm{~mm} \mathrm{Hg}$. We observed respiratory complications in 2 patients, surgical site infection in 3 patients, and chylothorax in 2 patients. No significant difference was observed in preoperative data and mortality rate ( 1 of 8 patients [12.5\%] in the Down syndrome group; 5 of 227 patients $[2.2 \%]$ in the non-Down syndrome group) between the groups of children with and without Down syndrome. However, when the postoperative clinical course was examined, the durations of intensive care unit stay $(P=.009)$ and hospital stay $(P=.007)$ were found to be significantly prolonged in the Down syndrome group.

Conclusions: Patients with Down syndrome tend to show prolonged recovery after TCPC. However, as opposed to previous reports, the mortality rate of patients undergoing TCPC is lower with no significant difference from that of children without Down syndrome. (J Thorac Cardiovasc Surg 2013;146:1349-52)
\end{abstract}

The Fontan operation for tricuspid atresia was first reported in 1971. Subsequently, the operation was modified several times and used for the treatment of other congenital heart diseases associated with a single functional ventricle. ${ }^{1}$ With improvements in treatment methods, the long-term prognosis and quality of life of patients with a Fontan circulation is gaining importance. ${ }^{2}$ However, the Fontan operation is rarely performed in children with Down syndrome ${ }^{3-6}$; therefore, the postoperative outcome for this group is not well known. Patients with Down syndrome are at risk of developing persistent pulmonary hypertension ${ }^{7}$ and airway obstruction, ${ }^{8}$ which may affect the outcome of univentricular repair. We report the result of total cavopulmonary connection (TCPC) performed in 8 children with Down syndrome.

\section{METHODS}

\section{Patients}

Between January 2004 and March 2010, 14 patients (11 boys and 3 girls) with Down syndrome among 240 total patients (120 boys and 120 girls) received a bidirectional superior cavopulmonary shunt

From the Departments of Pediatrics, ${ }^{\mathrm{a}}$ Juntendo University School of Medicine, Tokyo; and Departments of Pediatrics ${ }^{\mathrm{b}}$ and Pediatric Cardiovascular Surgery, ${ }^{\mathrm{c}}$ Sakakibara Heart Institute, Tokyo, Japan.

Disclosures: Authors have nothing to disclose with regard to commercial support.

Received for publication Oct 22, 2012; revisions received Jan 26, 2013; accepted for publication Feb 12, 2013; available ahead of print March 25, 2013.

Address for reprints: Takeshi Furukawa, Department of Pediatrics, Juntendo

University School of Medicine, 2-1-1 Hongo, Bunkyo-ku, Tokyo 113-8421, Japan

(E-mail: furukawa.tks@gmail.com).

$0022-5223 / \$ 36.00$

Copyright (C) 2013 by The American Association for Thoracic Surgery

http://dx.doi.org/10.1016/j.jtcvs.2013.02.017
(BCPS), whereas 8 patients with Down syndrome (6 boys and 2 girls) among 235 patients (121 boys and 117 girls) underwent TCPC, excluding TCPC conversion or repeat TCPC, at Sakakibara Heart Institute. All patients underwent BCPS before TCPC during this period.

\section{Clinical Protocol}

We investigated children with Down syndrome who had undergone univentricular repair. In particular we took note of the clinical course after BCPS and patient characteristics, preoperative catheter data, surgical data, preoperative echocardiographic data, type of Fontan operation, postoperative data and clinical course, and lung biopsy results. Postoperative catheter data and mortality were evaluated after TCPC. Patient characteristics, including clinical diagnosis, sex, age at TCPC, and body weight at TCPC were also investigated. Preoperative catheter data, including oxygen saturation, mean pulmonary artery pressure, and Nakata's pulmonary artery index $(\mathrm{PAI})^{9}$; and echocardiographic data, including aortic regurgitation and atrioventricular valve regurgitation, were graded as $0=$ absent, $1=$ trivial, 2 = mild, $3=$ moderate, or $4=$ severe. Postoperative data included central venous pressure (CVP) on entry into the intensive care unit (ICU), complications, index of pulmonary vascular disease, ${ }^{10}$ HeathEdwards classification as derived from lung biopsy examination, ${ }^{11}$ and postoperative oxygen saturation and CVP.

In addition, diagnostic category, preoperative catheter data, type of Fontan operation, postoperative data, clinical course, and mortality were compared between patients with Down syndrome (Down syndrome group, $\mathrm{n}=8$ ) and those without (non-Down syndrome group, $\mathrm{n}=227$ ). Postoperative data and clinical course were evaluated for the 2 groups with respect to the following parameters: CVP on entering the ICU, frequency of nitric oxide use, repeat surgery rate, duration of mechanical ventilation, duration of ICU stay, duration of pleural drainage, duration of hospital stay, and mortality. Mortality was categorized as either hospital death or late death (defined as death after discharge). We continued postoperative follow-up until December 2012. We evaluated all the above-mentioned parameters by performing a retrospective review of each patient's medical records. 


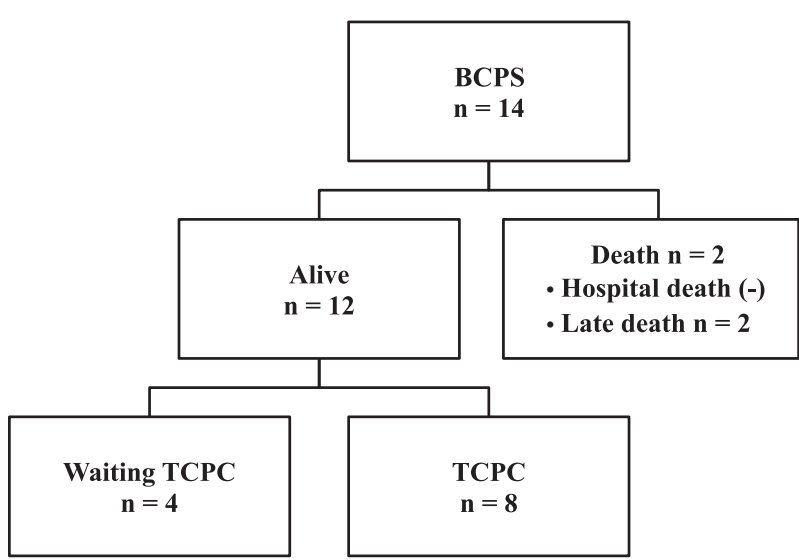

FIGURE 1. Cavopulmonary shunt and cavopulmonary connection in children with Down syndrome. $B C P S$, Bidirectional superior cavopulmonary shunt; $T C P C$, total cavopulmonary connection.

\section{Statistical Analyses}

StatView version 5.0 software (SAS Institute, Inc, Cary, NC) was used for all statistical analyses. The data are expressed as mean \pm standard deviation. Statistical significance was defined as $P<.05$. We used nonparametric tests to compare the parameters between the 2 groups. Differences in count or percentage data between the 2 groups were evaluated using $\chi^{2}$ analysis with Yates correction for continuity.

\section{RESULTS}

The clinical course of patients with Down syndrome who received a BCPS is shown in Figure 1. Fourteen patients with Down syndrome received a BCPS, with no hospital deaths and 2 late deaths. One patient died a sudden death 4 months after BCPS, whereas the other died as a result of heart failure 29 months after BCPS. Eight patients underwent TCPC, and 4 patients are still awaiting TCPC.

In the 8 patients with Down syndrome who underwent TCPC, the median age at the time of TCPC was 4.1 years (range, 3.4-5.5 years) and the mean body weight was $13.1 \mathrm{~kg}$ (range, 9.6-15.0 kg). The preoperative mean pulmonary artery pressure was $13.9 \pm 1.8 \mathrm{~mm} \mathrm{Hg}$, and PAI of all patients was above $200 \mathrm{~mm}^{2} /$ body surface area (in meters ${ }^{2}$ )
(Tables 1 and 2). We observed respiratory complications in 2 patients, surgical site infection in 3 patients, and chylothorax in 2 patients (Table 3). One patient (patient 2) died suddenly on postoperative day (POD) 17 because of a suspected pulmonary hypertension crisis. Results of lung biopsy obtained at autopsy revealed Heath-Edwards classification grade 3 and index of pulmonary vascular disease grade $\mathrm{D}$. There were no late deaths in the other patients. One patient developed protein-losing enteropathy 8 months after TCPC.

As shown in Table 2, there was no significant difference in preoperative data and diagnostic category between the groups of children with and without Down syndrome. However, there was no case of hypoplastic left heart syndrome and heterotaxy syndrome in the Down syndrome group. Mortality was higher in the Down syndrome group (1 of 8 patients, $12.5 \%$ ) than in the non-Down syndrome group ( 5 of 227 patients, $2.2 \%$ ), although this difference was not statistically significant (Table 4). However, when the postoperative clinical course was examined, the rate of nitric oxide use $(50.0 \%$ vs $7.9 \% ; P<.001)$ and that of repeat surgery $(25.0 \%$ vs $2.6 \% ; P=.015)$ were higher in the Down syndrome group than in the non-Down syndrome group. Patient 6 underwent surgery for an enlarged fenestration at POD 1, whereas patient 7 underwent repeat TCPC at POD 4. Furthermore, the duration of mechanical ventilation (7.8 \pm 6.9 days vs $2.6 \pm 8.2$ days; $P=.039$ ), duration of ICU stay (14.0 \pm 9.9 days vs $5.2 \pm 10.3$ days; $P=.009)$, duration of pleural drainage $(17.0 \pm 14.7$ days vs $9.7 \pm 10.3$ days; $P=.027$ ), and duration of hospital stay $(40.1 \pm 31.3$ days vs $27.7 \pm 17.0$ days; $P=.007)$ were found to be significantly prolonged in the Down syndrome group (Table 4).

\section{DISCUSSION}

Our study showed that the incidence of mortality after TCPC was $2.2 \%$ in the non-Down syndrome group and $12.5 \%$ ( 1 of 8 patients) in the Down syndrome group,

TABLE 1. Characteristics and preoperative data of patients in the Down syndrome group

\begin{tabular}{|c|c|c|c|c|c|c|c|c|c|}
\hline Patient & Diagnosis & Sex & Age, y & Weight, kg & $\mathrm{SpO}_{2}, \%$ & $\begin{array}{c}\text { Mean } \\
\text { PAP, } \text { mm Hg }\end{array}$ & PAI, $\mathrm{mm}^{2} / \mathrm{m}^{2}$ & $\begin{array}{c}\text { AR, } \\
\text { grade }\end{array}$ & $\begin{array}{c}\text { AVVR, } \\
\text { grade }\end{array}$ \\
\hline 1 & DORV, ASD, MS, Hypo-LV, CoA & Boy & 4.8 & 13.2 & 81.9 & 15 & 274 & 0 & 2 \\
\hline 2 & uAVSD, Hypo-LV, CoA, LVOTO & Boy & 2.4 & 9.6 & 80.1 & 11 & 305 & 0 & 2 \\
\hline 3 & $\mathrm{SLV}, \mathrm{CA}, \mathrm{CoA}$ & Boy & 5.5 & 14.4 & 89.0 & 15 & 490 & 0 & 1 \\
\hline 4 & VSD, ASD(II), Straddling MV, Straddling TV & Boy & 3.8 & 10.8 & 84.2 & 14 & 319 & 0 & 2 \\
\hline 5 & uAVSD, Hypo-RV & Boy & 4.3 & 11.3 & 79.8 & 13 & 240 & 0 & 0 \\
\hline 6 & uAVSD, Hypo-RV & Boy & 5.4 & 15.0 & 79.4 & 13 & 394 & 0 & 2 \\
\hline 7 & TOF, PA, uAVSD, Hypo-RV, PDA & Girl & 3.4 & 13.0 & 76.6 & 13 & 251 & 1 & 2 \\
\hline 8 & cAVSD, CoA, LVOTO & Girl & 3.8 & 14.7 & 74.0 & 17 & 447 & 1 & 1 \\
\hline
\end{tabular}

$\mathrm{SpO}_{2}$, Oxygen saturation; $P A P$, pulmonary artery pressure; $P A I$, pulmonary artery index; $A R$, aortic regurgitation; $A V V R$, atrioventricular valve regurgitation; $D O R V$, double out right ventricle; $A S D$, atrial septul defect; $M S$, mitral stenosis; Hypo- $L V$, hypoplastic left ventricle; $C o A$, coarctation of aorta; $u A V S D$, unbalanced atrioventricular septal defect; LVOTO, left ventricular outflow tract obstruction; $S L V$, single left ventricle; $M V$, mitral valve; $T V$, tricuspid valve; $H y p o-R V$, hypoplastic right ventricle; TOF, tetralogy of Fallot; $P A$, pulmonary atresia; $P D A$, patent ductus arteriosus; $C A$, common atrium; VSD, ventricular septal defect. 
TABLE 2. Comparison of preoperative data between groups of children with and without Down syndrome

\begin{tabular}{lccc}
\hline & $\begin{array}{c}\text { Down } \\
\text { syndrome } \\
(\mathbf{n = 8})\end{array}$ & $\begin{array}{c}\text { No Down } \\
\text { syndrome } \\
(\mathbf{n = 2 2 7})\end{array}$ & $\begin{array}{c}\boldsymbol{P} \\
\text { value }\end{array}$ \\
\hline Boys, n (\%) & $6(75)$ & $115(50.7)$ & .320 \\
Median age at TCPC operation, & $4.1(34-5.5)$ & $3.2(1.0-45.5)$ & .143 \\
$\quad$ y (range) & & & \\
Median weight, kg (range) & $13.1(9.6-15.0)$ & $12.9(6.7-69.1)$ & .136 \\
Diagnostic categories, n (\%) & & & \\
$\quad$ Function single LV & $4(50)$ & $75(33.0)$ & .537 \\
Function single RV & $2(25)$ & $52(22.9)$ & .772 \\
HLHS & 0 & $20(8.8)$ & .816 \\
Heterotaxy syndrome & 0 & $29(12.7)$ & .594 \\
Others & $2(25)$ & $51(22.5)$ & .793 \\
Preoperative catheter & & & \\
CVP, mm Hg & $7.43 \pm 1.72$ & $7.03 \pm 2.57$ & .344 \\
mPAP, mm Hg & $13.9 \pm 1.8$ & $13.6 \pm 3.0$ & .384 \\
PAI & $340.0 \pm 93.2$ & $282.3 \pm 118.4$ & .087 \\
AR & $0.25 \pm 0.46$ & $0.20 \pm 0.46$ & .388 \\
AVVR & $1.50 \pm 0.76$ & $0.98 \pm 0.99$ & .071 \\
\hline
\end{tabular}

$T C P C$, Total cavopulmonary connection; $L V$, left ventricle; $R V$, right ventricle; $H L H S$, hypoplastic left heart syndrome; $C V P$, central venous pressure; $m P A P$, mean pulmonary artery pressure; $P A I$, pulmonary artery index; $A R$, aortic regurgitation; $A V V R$, atrioventricular valve regurgitation.

although there was no significant difference between the 2 groups. Gupta-Malhotra and colleagues ${ }^{3}$ studied 17 patients with Down syndrome who underwent TCPC and reported that mortality in the early period was $29 \%$ and significantly higher than that in patients without Down syndrome $(10 \%)$.
They argued that Down syndrome itself is a strong independent factor of mortality. Our data indicate that there was no significant difference in preoperative data such as mean pulmonary artery pressure, PAI, aortic regurgitation, and atrioventricular valve regurgitation between the 2 groups, although the postoperative clinical course was prolonged significantly in the patients with Down syndrome. There were several patients in whom a serious postoperative clinical course was observed, and this could not be anticipated from the preoperative catheter data. Furthermore, the rates of nitric oxide use and repeat surgery were significantly high in the Down syndrome group in our study. One patient died suddenly as a result of a suspected pulmonary hypertension crisis, suggesting that it may be difficult to predict the outcome of TCPC on the basis of preoperative catheter data. Wada and colleagues ${ }^{5}$ reported the case of a patient who was awaiting Fontan surgery after BCPS. Although all criteria of TCPC had been fulfilled on the basis of preoperative hemodynamic studies, histologic analysis revealed hypertrophy of the tunica media in almost all preacinar small pulmonary arteries. Lung biopsy is an effective means of determining the outcome of TCPC in patients with Down syndrome.

Children with Down syndrome have a higher incidence of tracheal bronchus, abnormal segmental bronchial branching, laryngomalacia, and tracheomalacia. ${ }^{8}$ In our report, 2 of 8 patients developed respiratory tract disease as a complication, which was a reason for their long-term mechanical ventilation and prolonged ICU stay. There is evidence of a high incidence of chylothorax after Fontan

TABLE 3. Postoperative data of patients with Down syndrome

\begin{tabular}{|c|c|c|c|c|c|c|c|c|}
\hline \multirow[b]{2}{*}{$\underline{\text { Patient }}$} & \multirow[b]{2}{*}{ Type of operation } & \multirow[b]{2}{*}{$\begin{array}{c}\text { CVP, } \\
\text { mm Hg }\end{array}$} & \multirow[b]{2}{*}{ Complication } & \multirow[b]{2}{*}{$\begin{array}{c}\text { Respiration } \\
\text { problem }\end{array}$} & \multirow[b]{2}{*}{ Lung biopsy } & \multicolumn{2}{|c|}{ Postoperative catheter } & \multirow[b]{2}{*}{ Outcome } \\
\hline & & & & & & $\mathrm{SpO}_{2}, \%$ & $\begin{array}{c}\text { CVP, } \\
\mathrm{mm} \mathrm{Hg} \\
\end{array}$ & \\
\hline 1 & $\begin{array}{l}\text { Fenestrated extracardiac } \\
\text { conduit }\end{array}$ & 13 & No & No & Pre-TCPC IPVD 1.0, HE 1 & 82.8 & 14 & Alive (38 mo) \\
\hline 2 & Extracardiac conduit & 13 & No & No & Autopsy IPVD 1.7, HE 3 & Not done & & $\begin{array}{l}\text { Sudden death } \\
\text { (POD 17) }\end{array}$ \\
\hline 3 & Extracardiac conduit & 18 & $\begin{array}{l}\text { SSI } \\
\text { Chylothorax }\end{array}$ & Tracheostenosis & Not done & 91.0 & 17 & Alive (96 mo) \\
\hline 4 & $\begin{array}{l}\text { Fenestrated extracardiac } \\
\text { conduit DKS, lung } \\
\text { biopsy }\end{array}$ & 11 & No & No & At TCPC IPVD 1.0, HE 1 & 90.0 & 10 & Alive (42 mo) \\
\hline 5 & Extracardiac conduit & 15 & Chylothorax & No & Not done & 94.0 & 14 & $\begin{array}{l}\text { Alive } \\
\qquad \text { (85 months) }\end{array}$ \\
\hline 6 & $\begin{array}{l}\text { Fenestrated extracardiac } \\
\text { conduit, PA plasty } \Rightarrow \\
\text { Re-fenestration (POD 1) }\end{array}$ & 15 & SSI & No & Not done & Not done & & Alive $(27 \mathrm{mo})$ \\
\hline 7 & $\begin{array}{l}\text { Extracardiac conduit } \Rightarrow \\
\text { TCPC repair }(\text { POD } 4)\end{array}$ & 14 & Thrombosis & No & Not done & 92.0 & 12 & Alive (19 mo) \\
\hline 8 & $\begin{array}{l}\text { Fenestrated extracardiac } \\
\text { conduit }\end{array}$ & 15 & SSI PLE & $\begin{array}{r}\text { Laryngomalacia } \\
\text { Tracheal ring } \\
\end{array}$ & Not done & 94.5 & 11 & Alive (19 mo) \\
\hline
\end{tabular}

$\overline{C V P}$, Central venous pressure; $\mathrm{SpO}_{2}$, oxygen saturation; Pre-TCPC, preoperative total cavopulmonary connection; IPVD, index of pulmonary vascular disease; $H E$, HeathEdwards classification; $P O D$, postoperative day; SSI, surgical site infection; $D K S$, Damus-Kaye-Stansel operation; $P A$, pulmonary artery plasty; TCPC, total cavopulmonary connection; PLE, protein losing enteropathy. 
TABLE 4. Comparison of intraoperative and postoperative data for children with and without Down syndrome

\begin{tabular}{lccc}
\hline & $\begin{array}{c}\text { Down } \\
\text { syndrome } \\
(\mathbf{n}=\mathbf{8})\end{array}$ & $\begin{array}{c}\text { No Down } \\
\text { syndrome } \\
(\mathbf{n}=\mathbf{2 2 7})\end{array}$ & $\begin{array}{c}\boldsymbol{P} \\
\text { value }\end{array}$ \\
\hline Fontan type & & & $.031^{*}$ \\
$\quad$ Extracardiac nonfenestrated & $4(50.0)$ & $193(85.0)$ & \\
$\quad$ Extracardiac fenestrated & $4(50.0)$ & $34(15.0)$ & \\
CVP after Fontan surgery & $14.3 \pm 2.1$ & $13.7 \pm 2.1$ & .217 \\
Nitric oxide & $4(50.0)$ & $18(7.9)$ & $<.001^{*}$ \\
Repent surgery & $2(25.0)$ & $6(2.6)$ & $.015^{*}$ \\
Duration of mechanical ventilation, d & $7.8 \pm 6.9$ & $2.6 \pm 3.2$ & $.039^{*}$ \\
Duration of ICU stay, d & $14.0 \pm 9.9$ & $5.2 \pm 10.3$ & $.009^{*}$ \\
Duration of pleural drainage, d & $17.0 \pm 14.7$ & $9.7 \pm 10.3$ & $.027^{*}$ \\
Duration of hospital stay, d & $40.1 \pm 31.3$ & $27.7 \pm 17.0$ & $.007^{*}$ \\
Death & $1(12.5)$ & $5(2.2)$ & .500 \\
$\quad$ Hospital death & $1(12.5)$ & $4(1.8)$ & \\
$\quad$ Late death & 0 & $1(0.4)$ & \\
\hline
\end{tabular}

Values are presented as $\mathrm{n}(\%)$ or mean \pm standard deviation. $C V P$, Central venous pres sure; $I C U$, intensive care unit. $* P<.05$.

surgery in children with Down syndrome,${ }^{6}$ with Campbell and colleagues ${ }^{4}$ reporting this complication in 3 of 4 patients. In our study, 2 of 8 patients developed chylothorax that tended to prolong the duration of pleural drainage. Furthermore, 3 patients $(37.5 \%)$ developed surgical site infection. Down syndrome is associated with an increased frequency of infection, and several studies have reported immunologic dysfunction to be associated with Down syndrome. ${ }^{12-14}$ Abnormalities of the innate immune system and the prolonged duration of pleural drainage would be expected to predispose patients to surgical site infection and prolonged hospital stay.

In our study, only 8 patients with Down syndrome underwent TCPC, with the duration of follow-up being short. Various other complications are associated with Down syndrome, such as obstructive sleep apnea syndrome, ${ }^{15}$ obesity ${ }^{16}$ recurrent lower respiratory tract infections, and gastroesophageal reflux. ${ }^{17}$ Approximately $50 \%$ of children with Down syndrome develop obstructive sleep apnea syndrome, which may contribute to the unexplained pulmonary hypertension associated with Down Syndrome. ${ }^{18}$ Gastroesophageal reflux, pulmonary aspiration, and lower respiratory tract infections also increase the risk of pulmonary hypertension in these patients, ${ }^{19}$ and it is possible that they contribute to the development of this complication after TCPC. A longterm follow-up study with a larger number of patients with Down syndrome is therefore required, and it is also necessary to further evaluate the outcome of TCPC in these patients.

\section{Study Limitations}

Ours was a retrospective study with a short follow-up duration. In addition, the number of patients with Down syndrome was only 8 and significantly lower than that of patients without Down syndrome; this may have limited the results of the statistical evaluation of this study. Moreover, we made no mention of early palliative care in this investigation of univentricular repair.

\section{CONCLUSIONS}

We reported on 8 patients with Down syndrome who underwent TCPC. One of those 8 patients died after TCPC, whereas the clinical course and recovery after surgery in the other 7 patients was significantly prolonged. On the basis of these findings we consider it necessary to study more cases to evaluate mortality and long-term prognosis.

\section{References}

1. Fontan F, Baudet E. Surgical repair of tricuspid atresia. Thorax. 1971;26:240-8.

2. Marino BS. Outcomes after the Fontan procedure. Curr Opin Pediatr. 2002;14: 620-6.

3. Gupta-Malhotra M, Larson VE, Rosengart RM, Guo H, Moller JH. Mortality after total cavopulmonary connection in children with the down syndrome. Am J Cardiol. 2010;105:865-8.

4. Campbell RM, Adatia I, Gow RM, Webb GD, Williams WG, Freedom RM. Total cavopulmonary anastomosis (Fontan) in children with Down's syndrome. Ann Thorac Surg. 1998;66:523-6.

5. Wada N, Takahashi Y, Ando M, Park IS, Sasaki T. Single ventricle repair in children with Down's syndrome. Gen Thorac Cardiovasc Surg. 2008;56:104-8.

6. Sakurai H, Akita T, Kato N, Hasegawa H, Sakurai T, Sugiura J, et al. Short-term results of the Fontan operation in patients with Down syndrome [in Japanese]. Kyobu Geka. 2005;58:215-8.

7. Yamaki S, Yasui H, Kado H, Yonenaga K, Nakamura Y, Kikuchi T, et al. Pulmonary vascular disease and operative indications in complete atrioventricular canal defect in early infancy. J Thorac Cardiovasc Surg. 1993;106:398-405.

8. Bertrand P, Navarro H, Caussade S, Holmgren N, Sánchez I. Airway anomalies in children with Down syndrome: endoscopic findings. Pediatr Pulmonol. 2003;36: 137-41.

9. Nakata S, Imai Y, Takanashi Y, Kurosawa H, Tezuka K, Nakazawa M, et al. A new method for the quantitative standardization of cross-sectional areas of the pulmonary arteries in congenital heart diseases with decreased pulmonary blood flow. J Thorac Cardiovasc Surg. 1984;88:610-9.

10. Yamaki S, Tezuka F. Quantitative evaluation of hypertensive pulmonary arterial change. Acta Pathol Jpn. 1979;29:61-6.

11. Heath D, Edwards JE. The pathology of hypertensive pulmonary vascular disease; a description of six grades of structural changes in the pulmonary arteries with special reference to congenital cardiac septal defects. Circulation. 1958; 18:533-47.

12. Loh RK, Harth SC, Thong YH, Ferrante A. Immunoglobulin G subclass deficiency and predisposition to infection in Down's syndrome. Pediatr Infect Dis J. 1990;9:547-51.

13. de Hingh YC, van der Vossen PW, Gemen EF, Mulder AB, Hop WC, Brus F, et al. Intrinsic abnormalities of lymphocyte counts in children with down syndrome. J Pediatr. 2005; 147:744-7.

14. Cossarizza A, Ortolani C, Forti E, Montagnani G, Paganelli R, Zannotti M, et al. Age-related expansion of functionally inefficient cells with markers of natural killer activity in Down's syndrome. Blood. 1991;77:1263-70.

15. Southall DP, Stebbens VA, Mirza R, Lang MH, Croft CB, Shinebourne EA. Upper airway obstruction with hypoxaemia and sleep disruption in Down syndrome. Dev Med Child Neurol. 1987;29:734-42.

16. Cronk C, Crocker AC, Pueschel SM, Shea AM, Zackai E, Pickens G, et al. Growth charts for children with Down syndrome: 1 month to 18 years of age. Pediatrics. 1988;81:102-10.

17. Weir K, McMahon S, Barry L, Ware R, Masters IB, Chang AB. Oropharyngeal aspiration and pneumonia in children. Pediatr Pulmonol. 2007;42:1024-31.

18. Marcus CL, Keens TG, Bautista DB, von Pechmann WS, Ward SL. Obstructive sleep apnea in children with Down syndrome. Pediatrics. 1991;8:132-9.

19. Seki M, Kato T, Masutani S, Matsunaga T, Senzaki H. Pulmonary arterial hypertension associated with gastroesophageal reflux in a 2-month-old boy with Down syndrome. Circ J. 2009;73:2352-4. 